\title{
Evaluation Research of Unmanned Aerial Vehicle Communication System Efficiency
}

\author{
Yichen Song, Xiaotao Xu, Zhiqiang Lin and Liangqin Yu \\ Institute of Information and Communication, National University of Defense Technology, Wuhan, China
}

\begin{abstract}
This article chooses the ADC methodology which most suitable for the evaluation of aerial vehicle communication system efficiency. According to the characteristic of UAV Communication system and predictable information communication requirement as well as ADC model, this article rearrange the element system which based on information communication task and detailed the aggregated connection of index system of capacity matrix. This research proved the rationality and the feasibility of this methodology through example analysis. In additional, the accuracy and rigorism of this methodology has been improved. Besides, we also provide supportive and assistance for the effective decision-making process of UAC communication task.
\end{abstract}

Keywords-UAV Communication system; ADC modelevaluation of information communication efficiency

\section{INTRODUCTION}

Unmanned Aerial Vehicle refers to the pilotless aircraft controlled by remote control equipment or its own program. As an advanced air combat platform, compared with manned aircraft, it has the advantages of small volume, light weight, low cost, high maneuverability, good concealment and so on. It can accomplish the task that the pilot is not suitable for execution, so it has more and more tasks in the modern war, such as battlefield surveillance, supervision, electronic interference and so on. The evaluation of information and communication efficiency for UAV Communication system is an effective evaluation of the overall design concept of UAV Communication System and the advantages and disadvantages of UAV information and communication equipment. It is of great significance to maximize the efficiency of information communication.

\section{SElEct the EfFectiveness Evaluation Method of UAV COMMUNICATION SYSTEM}

System effectiveness refers to the effectiveness [1] when a weapon is used to carry out a specific task to achieve the desired target under certain conditions. The information communication effectiveness evaluation of UAV Communication system can be used in Lancester combat model, analytic hierarchy process, ADC method and SEA method. Considering the advantages and disadvantages of these methods, the ADC effectiveness evaluation model can be determined by the analytic hierarchy process without specific detailed parameters. The ADC method is a classic weapon system effective model for the first time in a research report by the WSE-IAC in the middle of 1960s. It takes the system state division and the conditional transfer probability as the modeling idea and evaluates the weapon system according to the three main factors of dependence between the effectiveness, the dependability, and the ability, and combine the three elements into a single effective degree of energy that represents the overall performance of the weapon system. The evaluation model is as follows:

$$
E=A \cdot D \cdot C
$$

The comprehensive operational effectiveness of the weapon system is a comprehensive measure of the ability of the system to complete the task. $E=\left(e_{i}\right)_{1 \times m}$ is the index vector of the system effectiveness. Its component $e_{i}$ represents the effectiveness index of the system for the $i$-th task; $A$ is the effectiveness index of the weapon system, reflects the advantages and disadvantages of the system combat readiness, $A=\left(a_{i}\right)_{1 \times n}$ is the system availability vector and its component $a_{i}$ representsthe probability of being in a state at the beginning of the execution of a task; $D$ represents the reliability index of a weapon system, reflecting the reliability of the system, $D=\left(d_{i j}\right)_{n \times n}$ is a system credibility matrix, whose component $d_{i j}$ represents the probability that the system is in state $i$ at the beginning of use and the probability of transferring to the state $j$ in the process of using the system; the inherent ability of the weapon system $C$ is the capability of the system. The component of a matrix $C=\left(c_{i j}\right)_{n \times m}$ indicates the probability that the system can accomplish the first task $j$ in the state $i$.

\section{BUILDING AN INFORMATION COMMUNICATION EFFICIENCY INDEX FOR UAV COMMUNICATION SYSTEM}

At present, the form of war is accelerating to information and intelligence. The integrated combined operation of realtime command and situation sharing has become the basic form of operation. The UAV has the advantages of small volume, low cost, unmanned, flexible maneuver and so on. It will become the tactical trend of joint operations. Therefore, according to the characteristics, system composition and foreseeable tasks of the UAV Communication system, we rebuilt an important index system for the information and communication efficiency of UAV Communication System on the basis of full consideration of its systematicness, hierarchy, objectivity and security, as shown in Figure 1: 


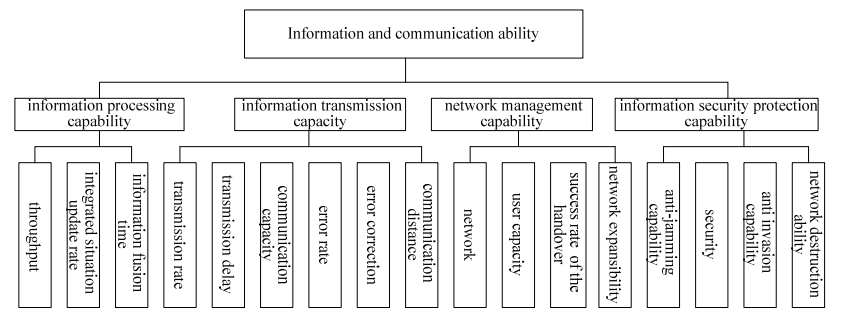

FIGURE I. INFORMATION COMMUNICATION CAPABILITY INDEX SYSTEM OF UAV COMMUNICATION SYSTEM

\section{ESTABLISH AN INFORMATION COMMUNICATION EFFECTIVENESS EVALUATION MODEL FOR UAV COMMUNICATION SYSTEM}

According to the effectiveness model, the process of legal efficiency analysis can be summed up, as shown in Figure 2. According to the index system of UAV Communication system, the information communication efficiency of UAV Communication system must be calculated, and the availability, credibility and capability matrix must be calculated.

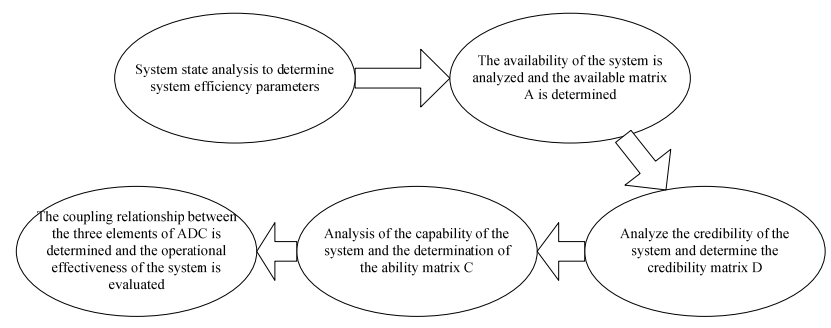

FIGURE II. FLOW CHART OF EFFECTIVENESS ANALYSIS OF ADC METHOD

\section{A. Determination of Availability Matrix}

We consider two situations of UAV Communication System with working state and fault state. In this case, there are only two components $a_{1}$ and $a_{2}$ of the available vector:

$$
A=\left[a_{1}, a_{2}\right]
$$

In (2) $a_{1}$ indicates the probability that an UAV Communication system can work at any time, and $a_{2}$ indicates the probability of being in a fault state at any time.

For any single platform system, the effectiveness of the system is:

$$
A=\frac{M T B F}{M T B F+M T T R}
$$

In Formula (3), MTBF is the mean time between failures and MTTR is the average repair time of the system.

If the failure rate and repair rate are known, when the system is in stable state, there are:

$$
\begin{aligned}
& a_{1}=\frac{M T B F}{M T B F+M T T R}=\frac{\mu}{\lambda+\mu} \\
& a_{2}=\frac{M T T R}{M T B F+M T T R}=\frac{\lambda}{\lambda+\mu}
\end{aligned}
$$

According to the two states of the existence of UAV, its available vector $\mathrm{A}$ is:

$$
A=\left[a_{1}, a_{2}\right]=\left[a_{1}, 1-a_{1}\right]
$$

\section{B. Determination of Reliability Matrix}

Since we only consider the two states of normal work and failure, the credibility matrix is a matrix of 2 orders, consisting of four elements:

$$
D=\left(\begin{array}{ll}
d_{11} & d_{12} \\
d_{21} & d_{22}
\end{array}\right)
$$

In (6), $d_{11}$ is the probability that the system is in a working state when the task is started and the system is in a working state when the task is completed; the system is in a working state when the task begins to execute, the probability of the system $d_{12}$ in a state of failure when the task is completed; the system is in a state of failure when the task is started and the system is in a state of failure. The probability $d_{21}$ that the system is in a working state at the time of a task; the probability $d_{22}$ that the system is in a state of failure when the task is started and the system is in a state of failure when the task is completed.

According to the experience and the statistics of the experimental data, it is found that the probability $d_{11}$ that the state of the UAV Communication system has been kept normal is exponential distribution, and its expression is $e^{-\lambda T}$, because $d_{11}+d_{12}=1$, we have $d_{12}=1-e^{-\lambda T}$. At the same time, we know that the UAV Communication system is in a state of failure at the beginning, and the probability of returning to normal is 0 during the execution of the mission, therefore $d_{12}=0$, and $d_{21}+d_{22}=1$, so $d_{22}=1$. We have:

$$
D=\left(\begin{array}{ll}
d_{11} & d_{12} \\
d_{21} & d_{22}
\end{array}\right)=\left(\begin{array}{cc}
e^{-\lambda T} & 1-e^{-\lambda T} \\
0 & 1
\end{array}\right)
$$

Type (7) represents the duration of a task, where $\lambda$ is the reciprocal of the mean time between failures.

\section{Determination Ability Matrix}

The capability matrix $C$ is the basis for determining the performance of the system, and also the concentrated embodiment of the system performance. This paper only considers the task of the UAV Communication system to 
perform the task alone. In the execution task, there are only two cases of normal work and failure state, so the ability matrix $C$ can be expressed as a two-dimensional column vector. Because the UAV Communication system is unable to perform tasks under the condition of failure, there are:

$$
C=\left[\begin{array}{l}
C_{1} \\
C_{2}
\end{array}\right]=\left[\begin{array}{l}
C_{1} \\
0
\end{array}\right]
$$

In formula (6), $c_{1}$ indicates the ability index of UAV Communication System working normally, and $c_{2}$ indicates the ability index of UAV Communication system failure. At this point, the process of computing ability matrix can be transformed into the process of solving $C_{1}$.

Index method is usually used to calculate the ability index, which includes two kinds of aggregation relations, additive relation and multiplicative relation. In order to make the evaluation efficiency $E$ more accurate and rigorous, this paper adopts the method of combining additive relation and multiplication relation to solve $c_{1}$.

The expression of the addition relation is:

$$
Z=\sum_{i=1}^{n} \mu_{i} X_{i}
$$

The aggregation relation of these indexes reflects the contribution degree of the lower index to the upper level index, and the same layer is complementary, and the zero value of any index will not lead to zero.

The expression of the multiplication relation is:

$$
Z=\prod_{i=1}^{n} X_{i}^{\mu_{i}}
$$

The aggregated relationship of these indicators reflects the indispensability of the lower level indicators to the upper level indicators, and the zero value of any index will cause the upper level index to be zero.

In form (9) and (10), we need to pay attention to two points. One is that the index $X_{i}$ is compared with the performance difference between the different equipment in the same information communication environment. It is used to compare the information and communication efficiency of different equipment, or by the comparison of the performance difference between the experts and the same equipment in different information and communication environment. The information communication efficiency of the equipment in different environments is estimated, and $0<X_{i}<1$. The other is that in the addition relation, the weighted coefficient can be obtained directly by the analytic hierarchy process, the greater the better the value, the smaller the better in the multiplication relation, and the empirical formula can be used in the calculation method.

$$
\mu_{i}=-\frac{\ln \omega_{i}}{\ln _{n}}
$$

In (11), $\omega_{i}$ is the weight of the index $X_{i}$ obtained by AHP, and $n$ is the total number of indicators.

According to the capability index of UAV Communication system, the relationship between these indexes and the upper level index is analyzed. We denote $C=c_{1}$ the ability index of the UAV Communication system, $L$ the information processing capability index, $S$ the information transmission capacity index, $G$ the network management capability index, and $F$ the information security protection capability index. Through analysis, we think that communication ability, detection ability and survivability are the necessary conditions to realize the UAV information and communication ability, and the lack of any UAV Communication system cannot accomplish the task of information and communication, so we should use the multiplication relation calculation capability index. The formula for calculating the capacity index is as follows:

$$
c_{1}=L^{\mu_{1}} \times S^{\mu_{2}} \times G^{\mu_{3}} \times F^{\mu_{4}}
$$

In formula (12), $\mu_{1}, \mu_{2} 、 \mu_{3} 、 \mu_{4}$ are the weighting coefficients.

In information processing capability $L$, we represent $T L$ the throughput index, $\mathrm{ZH}$ the integrated situation update rate index, $X X$ the information fusion time index. Through the analysis, we think that each index is a necessary condition for the realization of the UAV Communication ability, which is indispensable. Therefore, the calculation of the communication capability index $L$ is applied to the multiplicative relation, that is:

$$
L=T L^{\mu_{11}} \times Z H^{\mu_{12}} \times X X^{\mu_{13}}
$$

In formula (13), $\mu_{11} 、 \mu_{12} 、 \mu_{13}$ are the weighting coefficients.

In the information transmission capability $S$, we represent $S L$ the transmission rate index, $S Y$ the transmission delay index, $R L$ the communication capacity index, $W M$ the error rate index, $J C$ the error correction index, and $J L$ the communication distance index. Through the analysis, we also think that each index is a necessary condition for the realization of the UAV detection ability, so the calculation of the detection capability index $S$ is applied to the multiplicative relation, that is:

$$
S=S L^{\mu_{21}} \times S Y^{\mu_{22}} \times R L^{\mu_{23}} \times W M^{\mu_{24}} \times J C^{\mu_{25}} \times J L^{\mu_{26}}
$$


In formula (14), $\mu_{21} 、 \mu_{22} 、 \mu_{23} 、 \mu_{24} 、 \mu_{25} 、 \mu_{26}$ are the weighting coefficients.

In the network management ability $G$, we represent $Z W$ the network index, $Y H$ the user capacity index, $Y Q$ the success rate index of the handover, and $K Z$ the network expansibility index. Through the analysis, we think that any one of these indexes will not lead to the total loss of UAV fighting capacity, and these indexes have complementary relations. Therefore, the addition relation is used to calculate the combat capability index $G$. The formula is as follows:

$$
G=Z W^{\mu_{31}}+Y H^{\mu_{32}}+Y Q^{\mu_{33}}+K Z^{\mu_{34}}
$$

In formula (15), $\mu_{31} 、 \mu_{32} 、 \mu_{33} 、 \mu_{34}$ are the weighting coefficients.

In the same way, in the information security protection capability $F$, we represent $K G$ the anti-jamming capability index, represent $B M$ the security index, represent $F R$ the anti invasion capability index, and represent $W L$ the network destruction ability index. Through the analysis, we think that these indexes are the unnecessary conditions to realize the UAV survivability, that is, the lack of a certain index will not make the UAV's survivability completely lost, so we use the addition relation to calculate the UAV survivability index, and the calculation formula is as follows:

$$
F=K G^{\mu_{41}}+B M^{\mu_{42}}+F R^{\mu_{43}}+W L^{\mu_{44}}
$$

In formula (14), $\mu_{41} 、 \mu_{42} 、 \mu_{43} 、 \mu_{44}$ are the weighting coefficients.

\section{AN EXAMPLE ANALYSIS}

A certain type of UAV carries out a manoeuvre in a rainstorm environment, and a certain type of UAV carries out information and communication tasks during the exercise. Under normal circumstances, the average fault interval of the UAV Communication system is 36 hours and the average repair time is 4 hours. In the heavy rain environment, the average fault time of the UAV Communication system is 30 hours, and the average repair time is fixed. The time is 5 hours. The exercise time is 8 hours. After the exercise, the relevant experts are invited to evaluate the various indicators of the UAV Communication System during the exercise. The results of the evaluation are shown in the following table. The communication efficiency of UAV under normal environment and rainstorm environment is compared.

TABLE I. INDICATORS OF INFORMATION PROCESSING CAPACITY

\begin{tabular}{|c|c|c|c|}
\hline environment & $\begin{array}{c}\text { Through } \\
\text { put index }\end{array}$ & $\begin{array}{c}\text { integrated situation } \\
\text { update rate index }\end{array}$ & $\begin{array}{c}\text { information fusion } \\
\text { time index }\end{array}$ \\
\hline Normal environment & 0.55 & 0.57 & 0.50 \\
\hline $\begin{array}{c}\text { Rainstorm } \\
\text { environment }\end{array}$ & 0.45 & 0.43 & 0.50 \\
\hline
\end{tabular}

TABLE II. VARIOUS INDICATORS OF INFORMATION TRANSMISSION CAPACITY

\begin{tabular}{|c|c|c|c|c|c|c|}
\hline index & $\begin{array}{c}\text { transmi } \\
\text { ssion } \\
\text { rate } \\
\text { index }\end{array}$ & $\begin{array}{c}\text { transm } \\
\text { ission } \\
\text { delay } \\
\text { index }\end{array}$ & $\begin{array}{c}\text { commu } \\
\text { nication } \\
\text { capacity } \\
\text { index }\end{array}$ & $\begin{array}{c}\text { error } \\
\text { rate } \\
\text { index }\end{array}$ & $\begin{array}{c}\text { error } \\
\text { correct } \\
\text { ion } \\
\text { index }\end{array}$ & $\begin{array}{c}\text { communicat } \\
\text { ion distance } \\
\text { index }\end{array}$ \\
\hline $\begin{array}{c}\text { Normal } \\
\text { environment }\end{array}$ & 0.55 & 0.53 & 0.50 & 0.60 & 0.50 & 0.58 \\
\hline $\begin{array}{c}\text { Rainstorm } \\
\text { environment }\end{array}$ & 0.45 & 0.47 & 0.50 & 0.40 & 0.50 & 0.42 \\
\hline
\end{tabular}

TABLE III. EACH INDEX OF NETWORK MANAGEMENT ABILITY

\begin{tabular}{|c|c|c|c|c|}
\hline index & network & user capacity & $\begin{array}{c}\text { success rate } \\
\text { index } \\
\text { index } \\
\text { handover } \\
\text { index }\end{array}$ & $\begin{array}{c}\text { network } \\
\text { expansibility } \\
\text { index }\end{array}$ \\
\hline $\begin{array}{c}\text { Normal } \\
\text { environment }\end{array}$ & 0.50 & 0.55 & 0.65 & 0.50 \\
\hline $\begin{array}{c}\text { Rainstorm } \\
\text { environment }\end{array}$ & 0.50 & 0.45 & 0.35 & 0.50 \\
\hline
\end{tabular}

TABLE IV. EACH INDEX OF INFORMATION SECURITY PROTECTION CAPABILITY

\begin{tabular}{|c|c|c|c|c|}
\hline index & $\begin{array}{c}\text { anti- } \\
\text { jamming } \\
\text { capability } \\
\text { index }\end{array}$ & $\begin{array}{c}\text { security } \\
\text { index }\end{array}$ & $\begin{array}{c}\text { anti invasion } \\
\text { capability } \\
\text { index }\end{array}$ & $\begin{array}{c}\text { network } \\
\text { estruction } \\
\text { ability index }\end{array}$ \\
\hline $\begin{array}{c}\text { Normal } \\
\text { environment }\end{array}$ & 0.59 & 0.50 & 0.50 & 0.68 \\
\hline $\begin{array}{c}\text { Rainstorm } \\
\text { environment }\end{array}$ & 0.41 & 0.50 & 0.50 & 0.32 \\
\hline
\end{tabular}

According to the parameters of the information and communication performance index of the UAV Communication system, the information and communication efficiency under the normal environment and the rainstorm environment can be calculated according to the above formula.

Under normal conditions we have $E_{\text {normal }}=2.02 \times 10^{-3}$.

Under storm conditions we have $E_{\text {rainstorm }}=3.37 \times 10^{-4}$.

Therefore $E_{\text {normal }} / E_{\text {rainstorm }} \approx 6$.

The results show that the communication ability of the UAV Communication System in the heavy rain environment is far less than the information and communication ability under the normal environment. Therefore, the UAV should focus on its adaptability in the bad natural environment in the development or transformation.

\section{CONCLUSION}

Information communication effectiveness evaluation of UAV Communication system is a complex project. Through the analysis of the system efficiency method, this paper uses the ADC evaluation method combining qualitative and quantitative. According to the characteristics of the UAV Communication System and the foreseeable information and communication task, it restores the information and communication efficiency index system of the UAV Communication system, and carries out the information of the UAV Communication System with the ADC model. The 
communication efficiency is quantized and analyzed. The ability matrix is solved by the exponential algorithm combined with the combination of addition relation and multiplication relation, which improves the accuracy and rigour of the model. Finally, through the example, it is proved that the application of ADC model to the communication system of UAV Communication system is reasonable and feasible. The conclusion of this method is consistent with the reality. It has strong operability and practicability, and provides effective decision support and help for unmanned aerial vehicle (UAV) information communication task.

\section{REFERENCES}

[1] WANG YI DONG, LIU YI, SHI WEI FENG. Evaluation method of weapon equipment reliability index based on information communication efficiency[J]. Modern defense technology, 2011(5): 166170.

[2] ZHANG YONG JI, LI HUA,FAN JIN XIANG. Research on information and communication efficiency of UAV equipment. Winged missile, 2008(10): 13-16

[3] XU SHENG XIANG. Research on throry and method of information communication effectiveness evaluation of army information weapon equipment. BeiJing: Sea tide press. 2010.

[4] CAMBONE S A, KRIEGR, PACE P, et al Unmanned air-craft system roadmap 2005-2030[R]. Washington D.C: Office of the Secretary of Defense, 2005: 1-9.

[5] GAO XIA,XIONG JIAN. Concept and relevant technologies of cooperative operation for manned-unmanned aerial vehicles[J]. Telecommunication Engineering, 2014,54(12):1612-1616.(in Chinese)

[6] CHEN QIANG, CHEN CHANGXING, CHEN TING, et al Effectiveness evaluation of data link system based on ADC method[J]. Fire Control and Command Control, 2016,41(1):72-76(in Chinese)

[7] THOMAS J. Cooperative engagement: concept for a near team air- toair unmanned combat aircraft system[R]. Washington D.C :USA Force, 2006: 12-13.

[8] CC-AIR-IZMIR WG CDR J M PAIGE GBR AF. UAVs are set to mature[J]. The Journal of the JAPCC, 2006(3): 1-3. 